\title{
TamCrete structural support liner - a rapid polymeric structural support lining
}

T Kothe Normet International Ltd, Switzerland

\begin{abstract}
Normet's TamCrete SSL (structural support liner) was introduced one and a half years ago and is a reactive resin-based, rapid-curing, gas and watertight spray-applied shell. It is applied to a thickness of 5-10 mm and gains 70 to $80 \%$ of its peak strength within three to five minutes. This paper gives an overview on application methods, key mechanical properties and case studies. The major focus of the paper will be on field tests that have been executed at a hard rock site in Finland.
\end{abstract}

Keywords: thin support liner, sealant, support

\section{Introduction}

Thin support liners, or TSLS, have been used and tested over the past 30 years. TSLs are meant to be applied in a 3-10 mm thickness and consist of a certain polymer content. EFNARC (2008) (a European federation which unites national associations and companies involved in concrete repair, flooring, sprayed concrete and the protection and repair of tunnel and mining constructions) defines TSL as 'thin spray-on liner' and discusses guidelines for their use for non-structural rock support.

Existing TSLs on the market are either highly flexible polymer latex systems or polymer-modified mortars, both with curing times of some hours to days. TamCrete SSL is a new chemical approach that provides a more rigid structural lining support. It is a water-based resin which rapidly cures by radical polymerisation within two to four minutes.

\section{Site situation}

In most Scandinavian cities, water supply tunnels are in solid rock which can have unlined sections without a concrete lining. Some of these tunnels are now being upgraded, but logistically, the use of concrete is complicated or impossible where the supply pipes are installed and must not be removed. Tests were requested for a water supply tunnel (Figure 1) regarding the mechanical performance and future application quality of the TamCrete liner. The testing and onsite results are shown and discussed in the following sections.

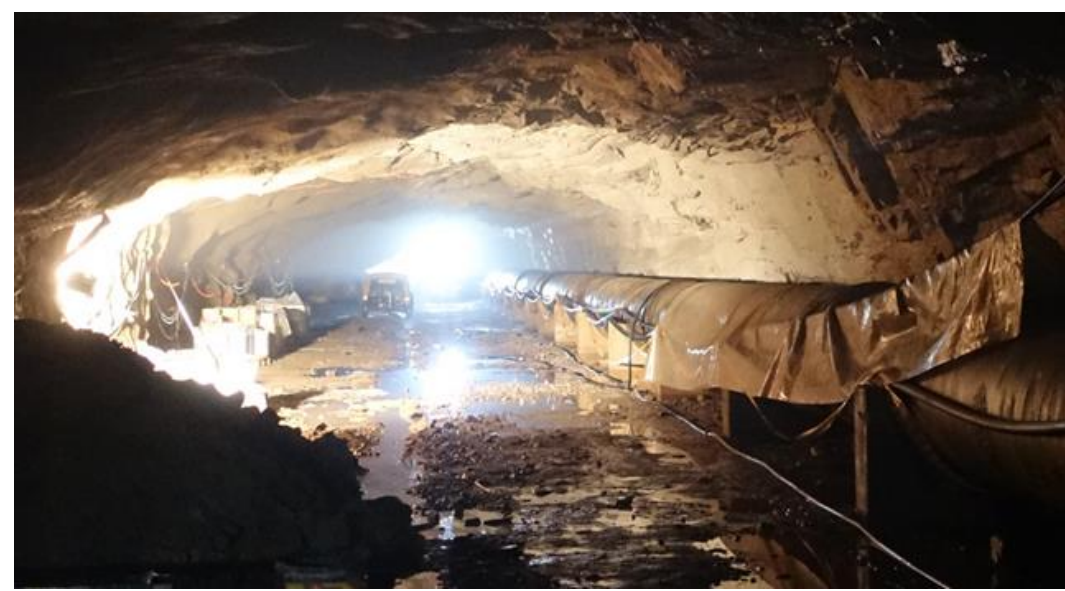

Figure 1 Granite tunnel with water supply pipe and TamCrete SSL as support liner in the crown 


\section{Onsite adherence tests (bond strength)}

\subsection{Method}

Pull-off strength tests were conducted in accordance with BS EN ISO 4624:2003 (British Standards Institution 2003) - the pull-off test for adhesion for resin-based materials. An onsite test device from Elcometer106 was used. This device is usually used for coatings on concrete and can measure adherence from 0-3.5 MPa. The scale of the test device is calibrated for $50 \mathrm{~mm}$ diameter pull stubs (dolly) showing $0.5 \mathrm{MPa}$ steps. The site test was modified since the standard drill bit had an outside diameter of $50 \mathrm{~mm}$ and only gave a $46 \mathrm{~mm}$ diameter test surface. As a consequence, the results are $18 \%$ higher than shown on the scale, and the corrected values are shown.

In addition, the contact area of the dolly to the glue and the TamCrete SSL surface was in most cases less than $100 \%$. In fact, it was between $60-80 \%$ for samples $1,3,4$ and 5 . This was not taken into account, and resulted in several tests failing at the glue-TamCrete interface.

The first five dollies were glued with Loctite Power Epoxy Universal 5' epoxy glue. The second series was glued with Araldite Rapid 2K epoxy glue. Both series cured for at least 20 hours at site.

\subsection{Results}

Table 1 gives an overview on the single adherence test results with Figure 2 showing typical samples at site.

Table 1 Sample numbers, results and failure node

\begin{tabular}{lll}
\hline $\mathbf{N r}$ & Adherence in MPa & Failure mode \\
\hline 1 & 0.59 & Failure in glue on SSL surface \\
2 & No result & Failure already in rock \\
3 & 0.59 & Failure in glue on SSL surface \\
4 & $>0.59$ & Failure in SSL, thin application $(1 \mathrm{~mm})$ \\
5 & No result & Glue failed when tester was installed \\
6 & 0.88 & Failure in glue on SSL surface \\
7 & $>0.59$ & Failure in SSL \\
8 & 0.88 & Failure in SSL \\
9 & 3.42 & Failure in SSL \\
10 & 0.59 & Failure in rock \\
\hline
\end{tabular}
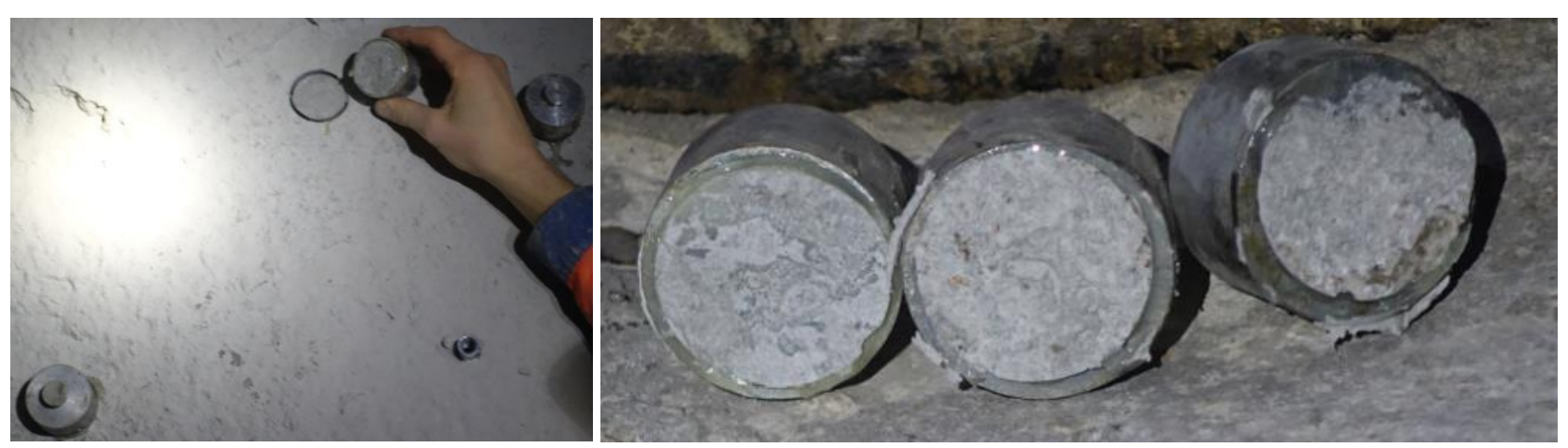

Figure 2 Onsite samples 6, 7 and 8 after adherence test 


\subsection{Discussion}

All samples reached the expected tensile adherence of $>0.5 \mathrm{MPa}$, however, they do not show the $>1 \mathrm{MPa}$ bond suggested by EFNARC (2008). The true adherence is clearly higher than the test results. The first five tests were mainly limited by the glue. However, even with the better glue used in tests 6 to 10, the failure is always on the SSL surface area. During application, a certain amount of reactive TamCrete SSL slurry is as mist in the air and will settle down in small spheres onto the thickly applied TamCrete liner with less bond to the cured TSL. It seems that this layer of settled mist is measured and needs to be removed in future tests. As a consequence, the results seem to reflect more the adherence between the cured TamCrete lining and settled and reacted material aerosols on top, rather than the bond to substrate. Only sample 9 showed an exceptionally high value and a failure within the structure. None of the samples failed at the rock interface.

\section{$4 \quad$ Block bearing capacity test}

Initially a drill core of rock from the crown was meant to be glued and covered with TamCrete SSL to test the block bearing capacity. As it turned out, the rock was too brittle and the initial test could not be executed. To measure the bearing capacity, four concrete panels were prepared and sprayed for pull-out tests as shown in Figure 3 instead. The diameter of the drill core was $114 \mathrm{~mm}$ and the resulting gap was 2-3 $\mathrm{mm}$ in width. The concrete core was put back so that the panel and core were ready to be coated with TamCrete SSL. Two panels were sprayed with two layers and the other two panels were sprayed with three layers of TamCrete SSL. As seen in Figure 4 showing the back side of the panel, TamCrete SSL penetrated and filled the whole gap made by the drill bit in the concrete panels. The panels are $50 \mathrm{~mm}$ thick.
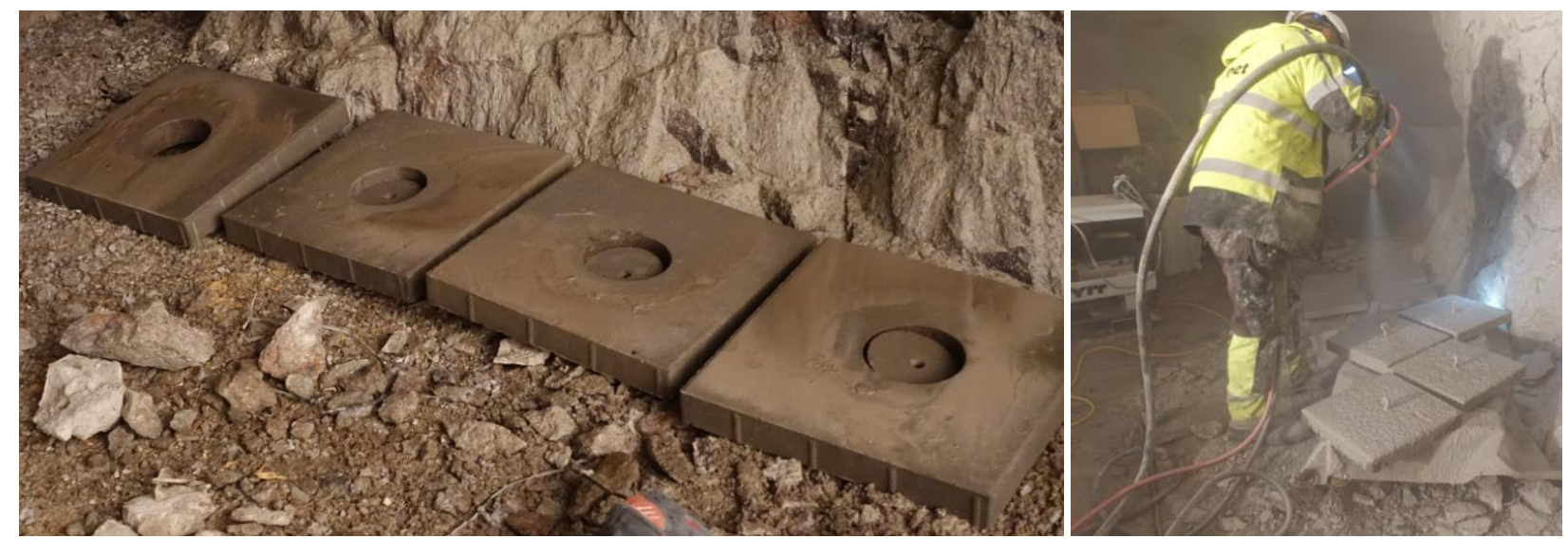

Figure 3 Sample preparation

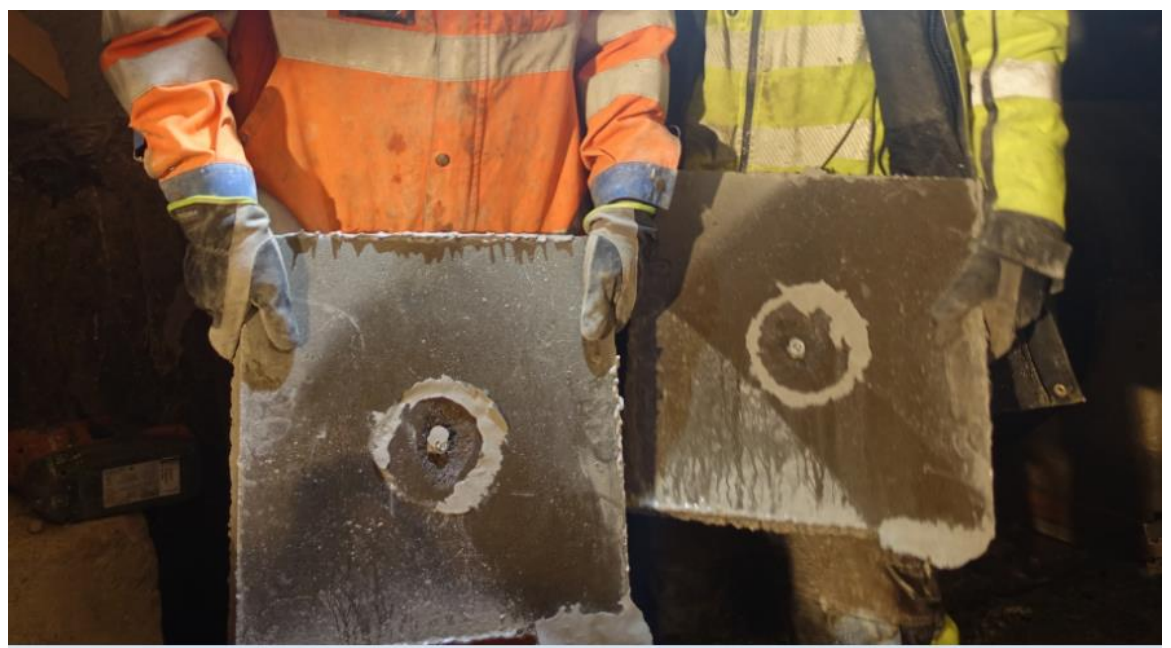

Figure 4 View on the back side. Penetration of SSL all through the gap 
For testing the bearing load of such simulated loose rock situations, an Enerpac 603 Hollow Plunger Cylinder was placed onto an extra steel frame and a maximum weight was measured at failure of the system, as indicated in Figure 5.
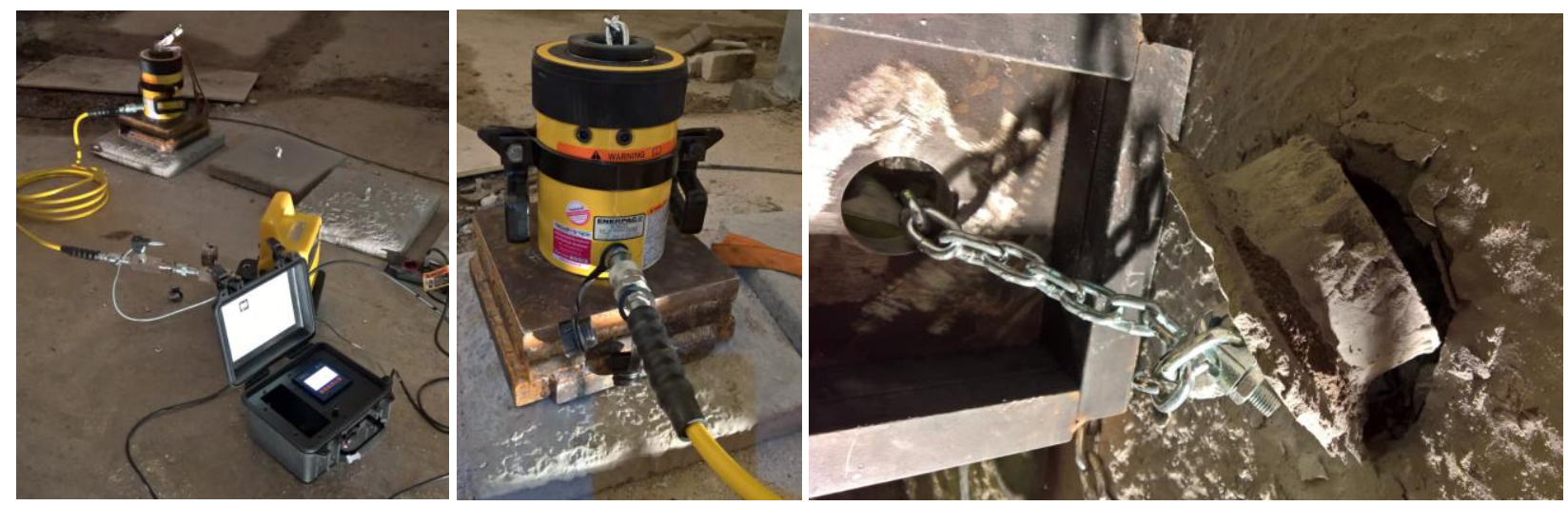

Figure 5 Test set-up

\subsection{Bock bearing results}

The failure load was evaluated approximately five weeks after application. Figure 6 shows all samples after the pull-out test. The failure mode varies strongly. While sample 1, with $10 \mathrm{~mm}$ thickness, failed within the concrete cylinder, sample 2 failed somehow in shear, sample 3 failed at the drilled pull-out anchor, and sample 4 ruptured in two parts. All samples resisted a strong load.

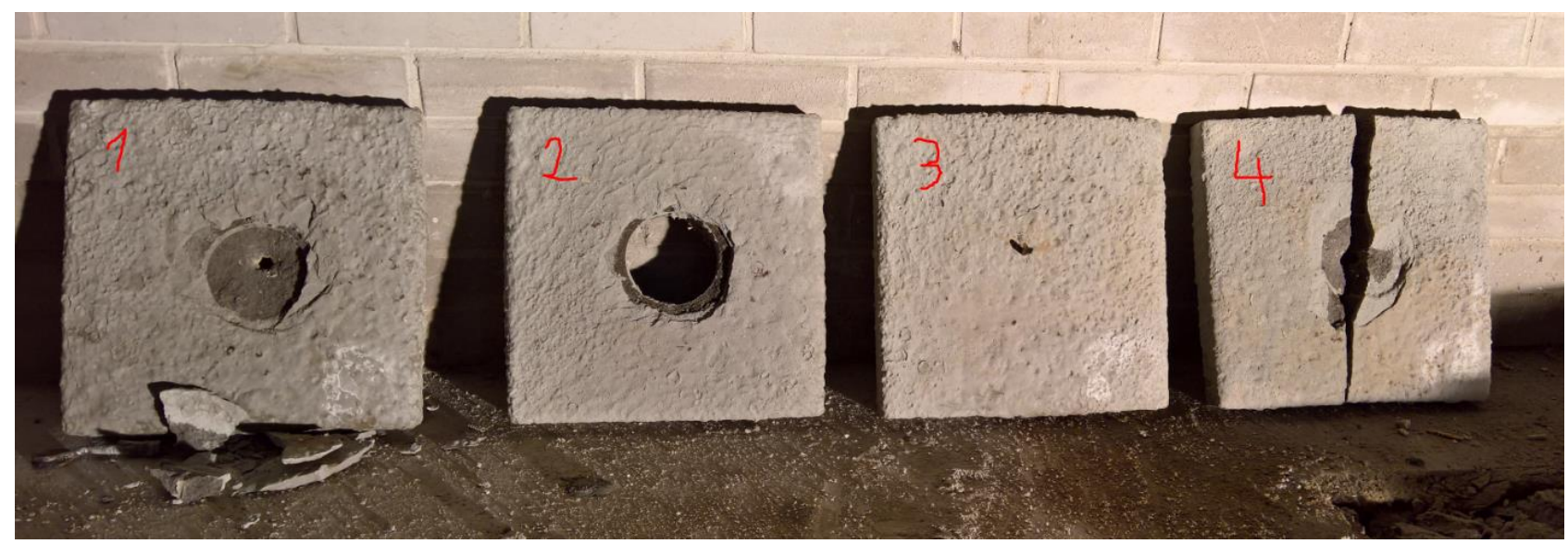

Figure 6 Samples 1-4 after pull-out test

The basic purpose was to simulate a situation in which a loose rock is glued with coverage and penetration to the surface. As a result, as shown in Table 2, we can see that a block of $11 \mathrm{~cm}$ diameter is kept in place up to a weight of $2 \mathrm{t}$. Since the geometrical set-up was complicated, with the steel frame and the anchor attached, this test applied already different stresses and forces onto the material. These results rely strongly on penetration of the SSL in cracks and the resulting shear force that may not exist when the material is applied onto rock. 
Table 2 Block bearing results

\begin{tabular}{lllll}
\hline & Applied layers & Total layer thickness $(\mathbf{m m})$ & Tonne & $\mathbf{k N}$ \\
\hline Sample 1 & 3 & 10 & 2.1 & 20.6 \\
Sample 2 & 2 & 8 & 1.8 & 17.6 \\
Sample 3 & 3 & 10 & 2.6 & 25.5 \\
Sample 4 & 2 & 8 & 2.5 & 24.5 \\
\hline
\end{tabular}

\section{$5 \quad$ Penetration into crack zones}

Finding cracks to drill in the already sprayed areas at site turned out to be very difficult. Two crack zones were found. Zone A had a crack 1.5-2 cm thick (Figure 7), while zone B had a 1-2 mm wide crack (Figure 8). Both zones were sprayed with TamCrete SSL and drill cores were taken to monitor the penetration of the product into the crack.
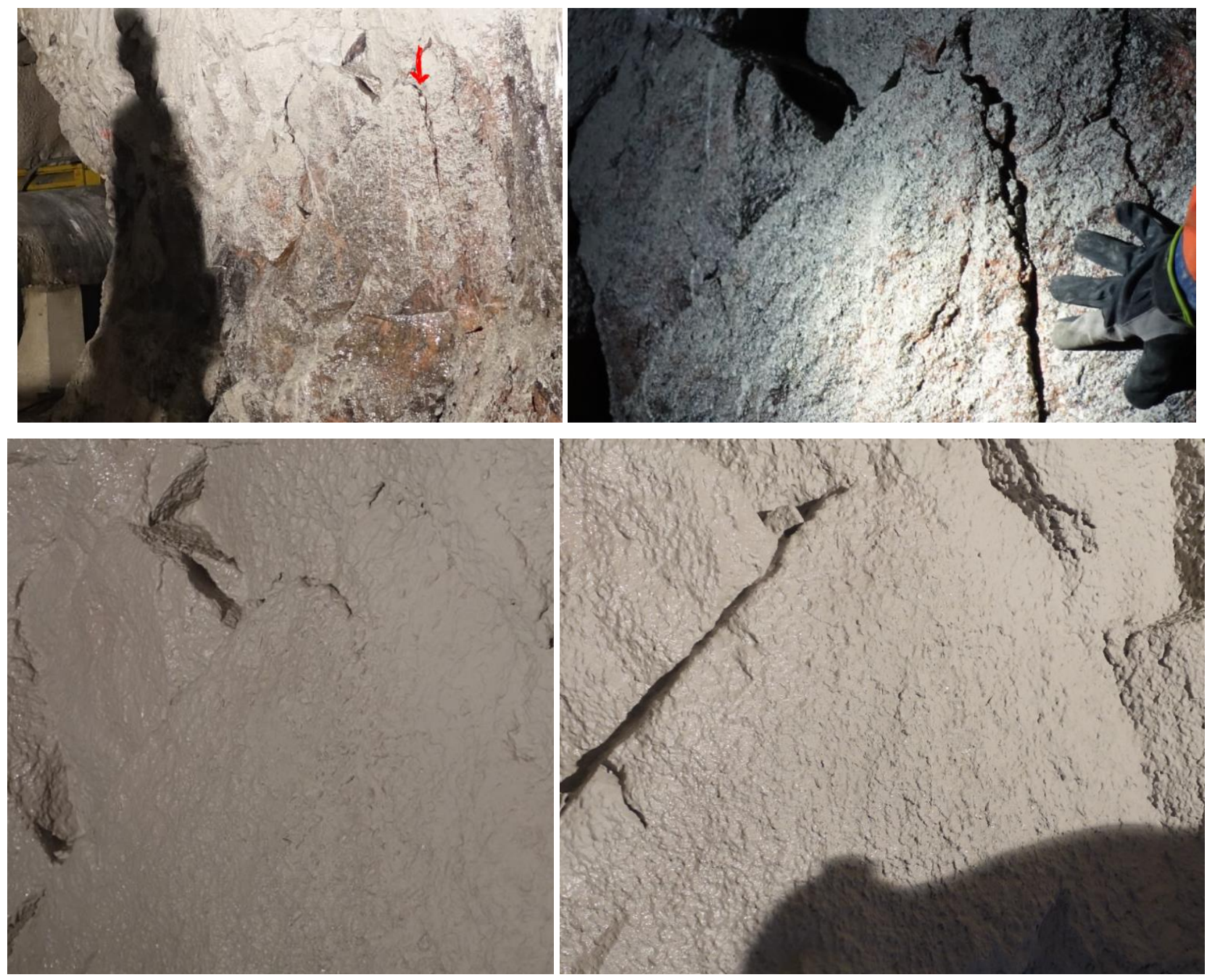

Figure 7 Pictures of zone $A$ before and after spraying 

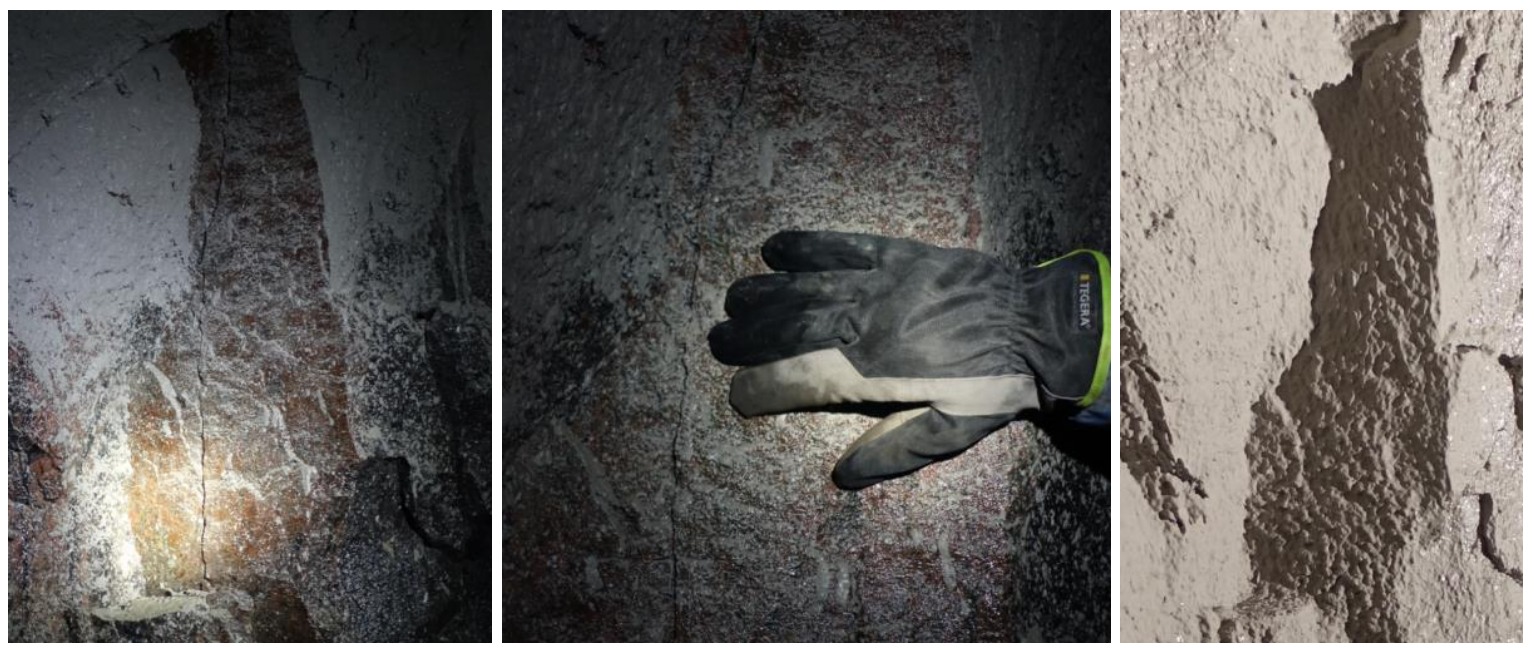

Figure 8 Zone B with a small crack of $1-2 \mathrm{~mm}$ only

\subsection{Results and discussion}

After spraying in zone A, drill cores were randomly taken and the crack zone visually inspected. The big gaps and voids were filled completely even though the spray angle could not be varied and was straight onto the surface. The drill cores often fell apart due to the fractured nature of the rock and the drilling process. Figure 9 shows good penetration of the SSL.
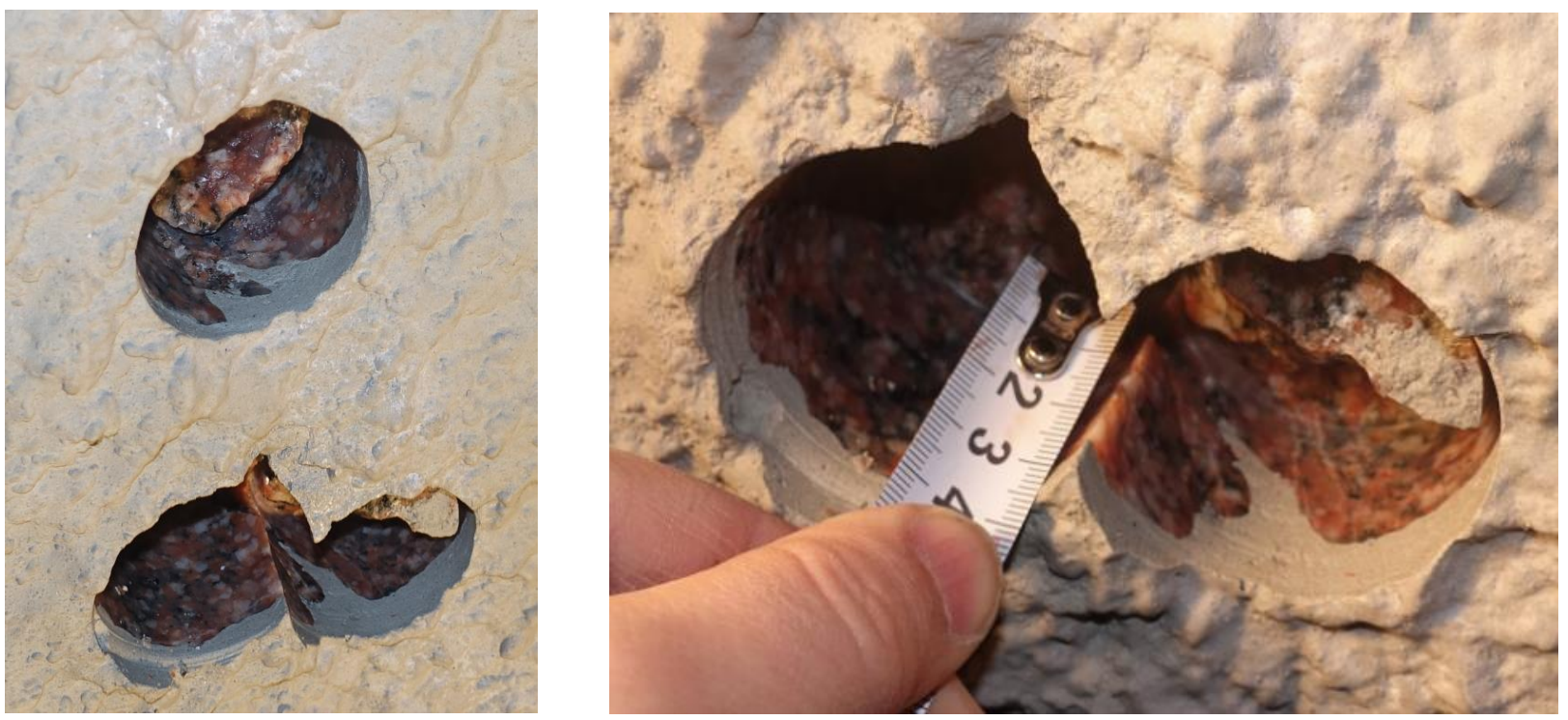

\section{Figure 9 Penetration depth zone $\mathrm{A}$}

Two cores were taken in zone B which intersected the cracked zone (Figure 10). One core fell apart and showed an area with $11 \mathrm{~mm}$ penetration into a $1 \mathrm{~mm}$ wide crack, while the other core showed $15 \mathrm{~mm}$ of penetration. In addition, the spray angle was not straight into the crack zone, but angled to the surface. 

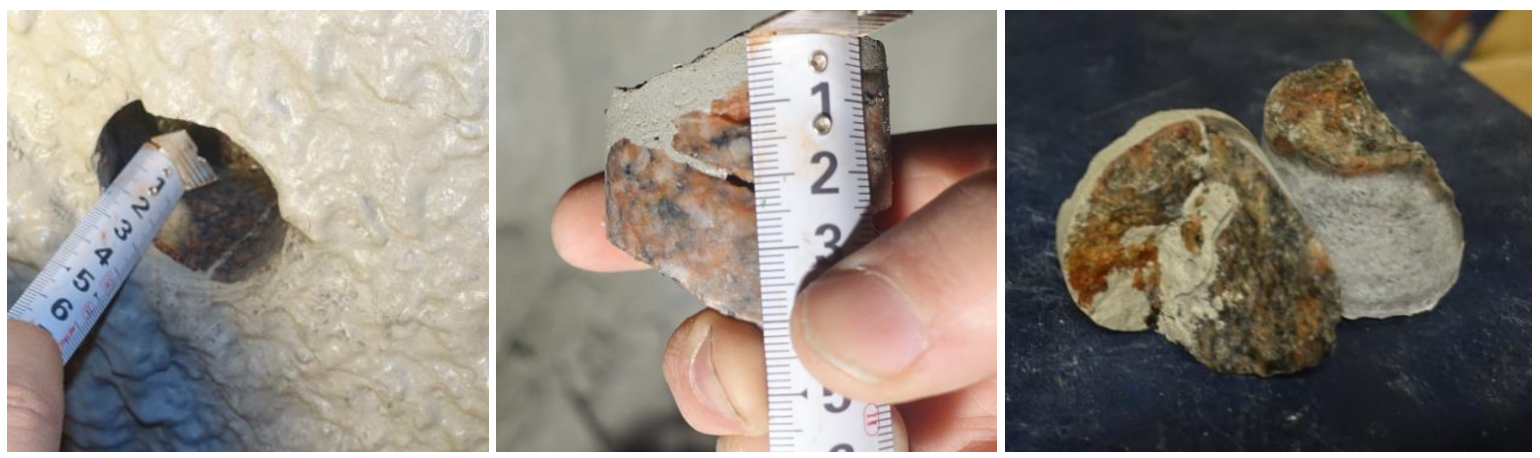

Figure 10 Penetration depth zone B

\section{Flexural and compressive strength}

SSL beams have been prepared for flexural and compressive tests according BS EN 1015-11 (British Standards Institution 1999) with $40 \times 40 \times 160 \mathrm{~mm}$ prisms. To achieve good prisms, the TamCrete SSL slurry was sprayed into polystyrene prism moulds.

\subsection{Results and discussion}

Flexural and compressive strengths have been tested in accordance with BS EN 1015-11 (British Standards Institution 1999) after 28 days. As shown in Figure 11, the three-point bending test is applied for a flexural strength test. The broken pieces have been used for compressive strength tests.
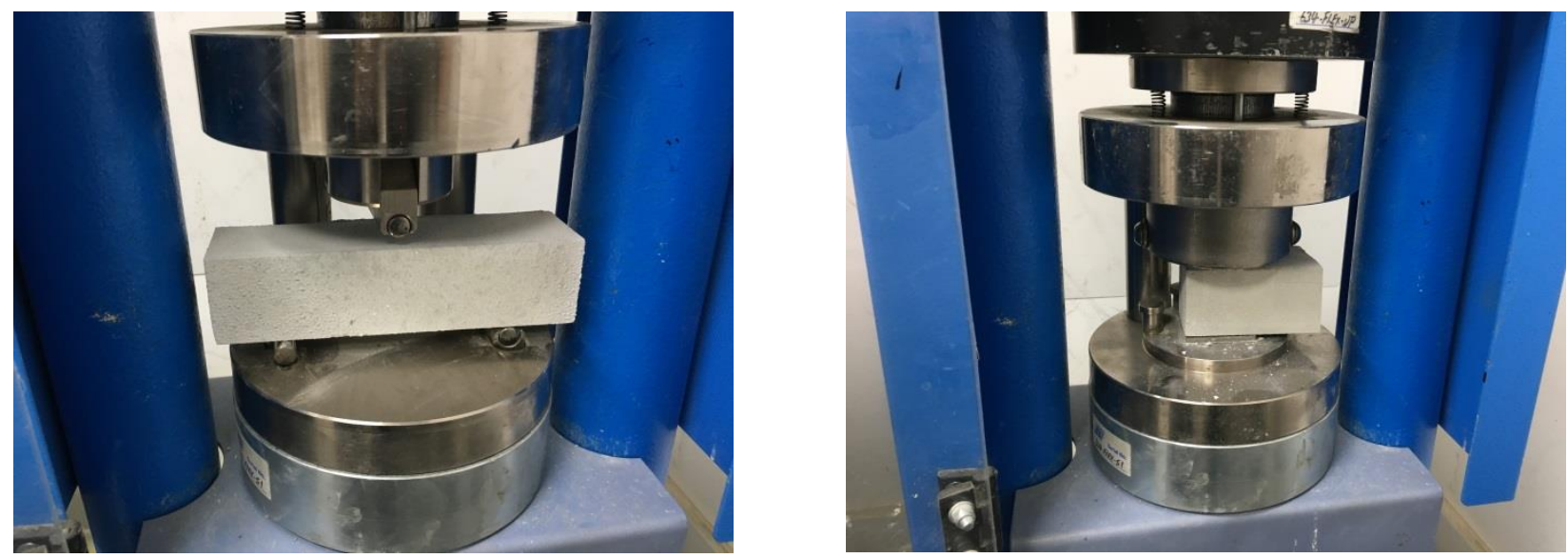

Figure 11 Flexural and compressive strength test device with SSL sample

The flexural strength has been calculated from the following equation:

$$
\sigma_{f}=\frac{3 F L}{2 B D^{2}}
$$

where:
$\sigma \quad=$ stress in outer fibres at midpoint (MPa).
$F \quad=$ load at a given point on the load deflection curve (N).
$L \quad=$ support span $(100 \mathrm{~mm})$.
$B \quad=$ width of test beam $(40 \mathrm{~mm})$.
$D=$ depth or thickness of tested beam $(40 \mathrm{~mm})$. 
The test results are summarised in Table 3.

Table 3 Compression and flexural strength results

\begin{tabular}{llllll}
\hline Sample & $\begin{array}{l}\text { Weight } \\
(\mathbf{g})\end{array}$ & $\begin{array}{l}\text { Flex load } \\
(\mathbf{k N})\end{array}$ & $\begin{array}{l}\text { Flex strength } \\
(\mathbf{M P a})\end{array}$ & $\begin{array}{l}\text { Compressive } \\
\text { load (kN) }\end{array}$ & $\begin{array}{l}\text { Compressive } \\
\text { strength (MPa) }\end{array}$ \\
\hline 1 & 428 & 1.74 & 4.08 & 21.22 & 13.26 \\
& & & & 19.94 & 12.46 \\
\hline 2 & 425 & 1.74 & 4.08 & 21.86 & 13.66 \\
& & & & 22.88 & 14.30 \\
\hline 3 & 444 & 1.66 & 3.89 & 18.47 & 11.54 \\
& & & & 18.80 & 11.75 \\
\hline
\end{tabular}

The results are in good agreement with Normet's technical data sheet (TDS) (Normet International 2016), stating $4 \mathrm{MPa}$ flexural strength and $14 \mathrm{MPa}$ in compression.

There are some factors that can affect the strength of the TamCrete SSL material. One important factor is the thickness of the material. Because the material is sprayed progressively, the material sets at different times. The thick material, i.e. $40 \mathrm{~mm}$ specimens, tend to have a layered structure that can cause lowered strength. It is expected that the thin layer applied material would give higher strength.

\section{Conclusion}

The adherence test showed a minimum 0.59 MPa bond strength. Penetration into crack zones is good; 11-15 mm penetration into 1-2 $\mathrm{mm}$ wide cracks under difficult angles was achieved. In a simulation of bearing load from loose rock, a $2 \mathrm{t}$ block could be supported through a combination of support from a surface spray and from SSL penetration into cracks. Standard tests need to be conducted so results can be compared to other TSL products.

Flexural strength of $4 \mathrm{MPa}$ and compressive strength of $12.8 \mathrm{MPa}$ are fully in line with the values given on the Tamcrete SSL TDS (Normet International 2016) even after being sprayed under realistic site conditions.

TamCete SSL is a new support liner and has undergone initial testing in field conditions. Tests show strength values less than that for sprayed concrete and additional standard testing is required. However, it is not the final strength that is of interest, but the instant strength the system provides. The rapid curing of this system gives new opportunities in both tunnelling and mining operations.

\section{References}

British Standards Institution 1999, BS EN 1015-11:1999, Methods of Test for Mortar for Masonry, Determination of Flexural and Compressive Strength of Hardened Mortar, British Standards Institution, London, viewed 30 May 2017, http://shop.bsigroup.com/ProductDetail/?pid=000000000030151094

British Standards Institution 2003, BS EN ISO 4624:2003, Paints and Varnishes, Pull-off test for Adhesion, British Standards Institution, London, viewed 30 May 2017, http://shop.bsigroup.com/ProductDetail/?pid=000000000030081393

EFNARC 2008, Specification and Guidelines on Thin Spray-on Liners for Mining and Tunnelling, EFNARC, viewed 30 May 2017, http://www.efnarc.org/pdf/ENC\%20250TSL\%20v7.2\%2025-07-08_r1.pdf

Normet International 2016, Tamcrete SSL TDS (Technical Data Sheet), available from Normet International on request. 